\title{
An Analysis of Information Literacy and Attitudes towards e-Learning of Elementary School Teachers
}

\author{
York Min-Yu Sun, Rong Jou Yang, Hann-Jang Ho, and Yu-Fen Chang
}

\begin{abstract}
With the advancement of information technology, researches of e-learning have rapidly changed in focus and breadth over the last several decades as consequence of changes in educational tools, policies and practices. For elementary school teachers, they must constantly update their knowledge and skills in the field of information and education to remain competitive. The objective of this study is to understand the effect of information literacy and attitudes towards e-Learning of primary school teachers' willingness in Chiayi County, Taiwan. This study employed questionnaire survey to analyze relationship between teachers' information literacy and attitudes towards e-Learning. There was a total of 124 schools surveyed for the study. 232 Questionnaires were dispatched to over 18 villages and towns in Chiayi County. A total of 218 valid questionnaires was received and the valid response rate was 93.4\%. Questionnaire data was analyzed by descriptive statistics, t-Test, one-way ANOVA, and Pearson's correlation coefficient. The results indicated that there was a strong correlation between information literacy and attitudes towards e-Learning of primary school teachers' willingness in Chiayi County, Taiwan.
\end{abstract}

Index Terms-Information literacy, e-learning, t-test, one-way ANOVA, pearson's correlation.

\section{INTRODUCTION}

The application of information technology (IT) in social and human life has appeared in an explosive development in 21st Century. Information literacy (IL) has evolved as a strategy of knowledge management, which has become a factor of competitive advantage and the best communication channel between human being and information around it. IL is to integrate all these abilities and able to assist people in manipulating a wide variety of information. To adapt to the coming of the era of globalization and the promotion of potential competition of the student, we must focus on advances in knowledge economy to foster competitive capacity of students. In wave [1] of revolution of e-learning and low birth rate as indicated in Fig. 1, how to apply innovative information media technology in learning to promote competitive capacity of individual and schools

Manuscript received October 28, 2016; revised May 2, 2017.

York Min-Yu Sun and Hann-Jang Ho are with the Department of Applied Digital Media, WuFeng University, Min-Hsiung, Chiayi County, 625, Taiwan (e-mail: york@wfu.edu.tw, hhj@wfu.edu.tw).

Rong Jou Yang was with WuFeng University, Min-Hsiung, Chiayi County, 625, Taiwan. He is now with the Department of Computer Science, the University of Texas at El Paso, El Paso, TX 79968 USA (e-mail: ryang@miners.utep.edu).

Yu-Fen Chang was with WuFeng University, Min-Hsiung, Chiayi County, Taiwan. She is now with the Guogou Elementary School, Budai, Chiayi County, 625, Taiwan (e-mail: hcc34327@ms19.hinet.net). whenever necessary is one of important issues that is faced by nowadays school teachers.

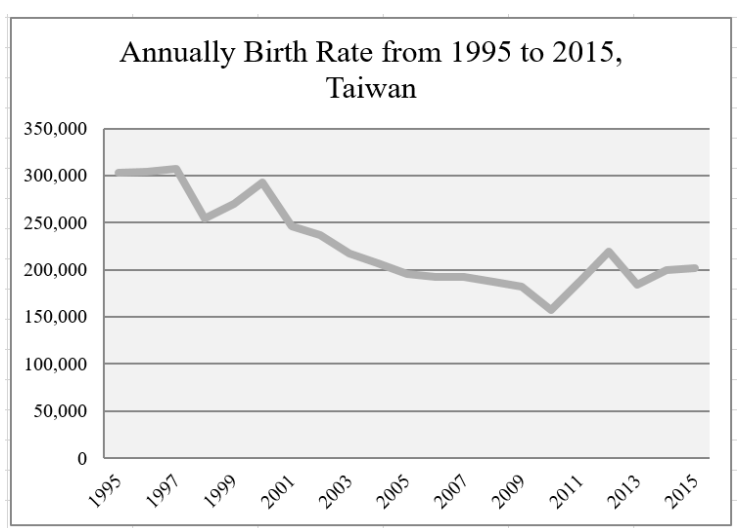

Source: Summarized by Researchers from Department of Statistics, Taiwan. Fig. 1. Annually birth rate from 1994 to 2012.

\section{RESEARCH Motives AND PURPOSES}

\section{A. Research Motives}

In the beginning of e-era, how to master in demanded IL to be qualified for new challenge was focus of social concerns. IL no doubt is the important key [2].

Nowadays elementary and high school teachers would play multiple roles, not only the role of "knowledge transfer" but more important also of "knowledge navigator." If elementary and high school teachers possess IL and can imply IT facilities in teaching activities or processes was one of our motives of this research.

The changing environment is due to progress of Internet and IT. Recently Minister of Education (MOE), Taiwan has furthered the educational initiative in e-learning such as the implementation of e-learning platform.

To understand what is the school teachers' attitudes towards e-learning was the second motive of this research. The pedagogy will be entrenched to traditional teaching method without innovation if they don't have IL. To understand the correlation of individual background, IL, and e-learning via an empirical study was the third motive of this research.

\section{B. Research Purpose}

The purposes of research are classified as follows based on the motives above:

1) Understanding the current states of teachers' IL and attitudes towards e-learning.

2) Understanding if difference of teachers' IL and attitudes towards e-learning exists due to individual background.

3) Understanding correlation between teachers' IL and 
attitudes towards e-learning.

\section{LITERATURES}

\section{A. Meaning and Research of IL}

$\mathrm{IL}$ is a concept as well as a technique solving the problem by implying information. The information consisted of traditional, computer, media, and network literacy and IL is the core of the four literacies [3]. IL is an element towards information society, which is not only demanded by academic research but also other sectors to boost efficiency and quality of services [4] IL was derived from the word "Literacy" which was coined by Zurkowski, the Chairman of Association for Library and Information Science Education in 1974 [5] and mainly refers to "individual having the abilities to search, evaluate, and utilize a variety of sources of information."

In [6], Lin (2007) proposed that the meaning of teachers' IL referred to teachers' recognition and using of IT and further integrated IT into a wide variety of teaching activities to promote teaching effect as well as foster student the abilities of IL and IT application. Summarized related researches of IL, we found that background variables such as sex, age, education, seniority, position, usage of computer facility, and on-job training and environment variables such as school of scale, location of school, and computer facility are important factors which affect teachers' IL.

\section{B. Meaning and Research of Attitudes towards e-Learning}

In [7], Wu (2004) indicated that e-learning and networked learning refer to the learning activities by utilizing information communication technology (ICT), especially Internet dissemination or resources to conduct learning activities. To extend and expand the scope of individual, learning was just the general concept of life-time learning.

\section{RESEARCH METHODS}

In this research, we first analyzed and compared related theoretical concept and research method of IL based on literatures. Secondly, we surveyed the related literatures of teachers' and government employee' attitudes towards e-learning and analyzed the characteristic of e-learning. Third, we proposed the research architecture as indicated in Fig. 2, based on our research purpose.

\begin{tabular}{|c|c|}
\hline Background Variable & Information Literacy \\
\hline Sex & Recognition of IT \\
\hline Age & Ability of Oper. HW/SW \\
\hline Seniority & Ability of Network App. \\
\hline Education Background & IT Integrated Teaching \\
\hline Position & Communic. \& Repr. of Info. \\
\hline School of Scale & 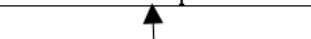 \\
\hline \multirow{6}{*}{$\begin{array}{l}\text { Average Computer Use } \\
\text { Time per Week per } \\
\text { Person }\end{array}$} & $\boldsymbol{\nabla}$ \\
\hline & Attitudes towards E-learning \\
\hline & Affection of E-learning \\
\hline & Confidence of E-learning \\
\hline & Anxiety of E-learning \\
\hline & Practicality of E-learning \\
\hline
\end{tabular}

Fig. 2. Research architecture.

We also developed the questionnaire to conduct the survey and analyzed by employing SPSS to elucidate the correlation of IL and attitudes towards e-learning.

There were 1,418 classes of 124 elementary schools of 18 villages and towns in Chiayi County. The sampling size was 232 questionnaires dispatched to 15 sampled schools and 218 questionnaires was collected, which was $93.4 \%$ of response rate. In this questionnaire survey, reliability of IL was verified based on five facets, in which Cronbach's coefficient $\alpha$ was between 0.655 and 0.874 . And on entirety was 0.920 . Reliability of e-learning was verified based on five facets, in which Cronbach's coefficient $\alpha$ was between 0.838 and 0.913 and on entirety was 0.897 , which showed the internal consistency of reliability.

\section{RESEARCH RESUlTS}

In this section, we first analyzed the differences between teachers' IL and attitudes towards e-learning based on background variables such as sex, age, seniority, educational background, position, school of scale, and average computer use time per week per person.

\section{A. States of IL and Attitudes towards e-Learning}

By employing descriptive statistics, the average and standard deviation of teachers' IL in entirety and in five facets of recognition of IT, ability of operating hardware/software, ability of network application, IT integrated teaching, and communication and representation of information were indicated in Table I.

TABLE I: SUMMARY OF ENTIRETY AND ALL FACETS OF IL

\begin{tabular}{cccc}
\hline Facets & Score Order & AVG & STD \\
\hline Ability of Opera HW/SW & 2 & 4.5028 & 0.48164 \\
\hline Ability of Network App & 3 & 4.2966 & 0.50667 \\
\hline Recognition of IT & 1 & 4.6231 & 0.38669 \\
\hline IT Integrated Teaching & 4 & 4.2633 & 0.50127 \\
\hline Communic. \& Repr of Info & 5 & 4.0161 & 0.69459 \\
\hline Entirety & & 4.3404 & 0.41758 \\
\hline
\end{tabular}

The averages were greater than 4 in all facets of IL, which meant teachers' IL was excellent, especially in the facet of recognition of IT which ranked the first, ability of operating hardware/software the second, and the facets of ability of network application, IT integrated teaching, and communication and representation of information in decreasing order. The results might attribute to the complete network environment of information, diversity of $3 \mathrm{C}$ products, and popularization of network infrastructure. The good IL in the facet of network application might also attribute to the ordinary Internet searching of related information of $3 \mathrm{C}$ products in school or at home and communicating and sharing with other people.

Secondly, the average in entirety of attitudes towards e-learning was 3.7828 which ranked middle level based on Likert scale, especially in the facet of confidence of e-learning which ranked the first and practicality of e-learning the second as indicated in Table II.

\section{B. Impact of Background Variables and IL}

Sex made significant difference $(t=2.512, p<0.05)$ in the facet of ability of network application and the average 
indicated that male was higher than female. But in the facets of ability of operating hardware/software, IT integrated teaching, communication and representation of information, and entirety of IL, sex made no significant difference.

TABLE II: SUMMARY IN ENTIRETY AND FOUR FACETS OF ATTITUDES TOWARDS E-LEARNING

\begin{tabular}{c|c|c|c}
\multicolumn{4}{c}{ TOWARDS E-LEARNING } \\
\hline Facets & Score Order & AVG & STD \\
\hline Affection of E-learning & 3 & 3.8372 & .63549 \\
Confidence of E-learning & 1 & 4.1239 & .51546 \\
Anxiety of E-learning & 4 & 2.9392 & .89965 \\
Practicality of E-learning & 2 & 4.0333 & .64158 \\
Entirety & & 3.7828 & .51197 \\
\hline
\end{tabular}

Age made significant difference $(F=5.032, p<0.01)$ in the facet of ability of operating hardware/software. After post comparison by employing Scheffè method, we found that the ability of operating hardware/software of age less than 40 was better than age greater than 50 .

Seniority made no significant difference in entirety and all facets of IL.

Educational Background made significant difference ( $F=$ 4.081, $p<0.01)$ in the facet of communication and representation of information. After post comparison by employing Scheffè method, we found that graduate school were better than undergraduate. But Educational Background made no significant difference in all facets of IL.

TABLE III: IL WITH DIFFERENT POSITIONS

\begin{tabular}{|c|c|c|c|c|}
\hline Facet & Position & $\mathrm{AVG}$ & $\mathrm{F}$ & Post Comparison \\
\hline \multirow{5}{*}{$\begin{array}{l}\text { Ability of Operating } \\
\text { HW/SW }\end{array}$} & (1) Mentor & 4.5098 & \multirow{5}{*}{$6.505 * * *$} & \multirow{5}{*}{$\begin{array}{l}(1)>(2) \\
(3)>(2) \\
(4)>(2) \\
(5)>(2)\end{array}$} \\
\hline & (2) Teacher & 4.0870 & & \\
\hline & (3) Adm. mentor & 4.5846 & & \\
\hline & (4) Group Leader & 4.5500 & & \\
\hline & (5) Chair & 4.7214 & & \\
\hline \multirow{5}{*}{$\begin{array}{l}\text { Ability of Network } \\
\text { Application }\end{array}$} & (1) Mentor & 4.2459 & \multirow{5}{*}{2.216} & \multirow{5}{*}{ null } \\
\hline & (2) Teacher & 4.1449 & & \\
\hline & (3) Adm. mentor & 4.3590 & & \\
\hline & (4) Group Leader & 4.4271 & & \\
\hline & (5) Chair & 4.4643 & & \\
\hline \multirow{5}{*}{ Recognition of IT } & (1) Mentor & 4.5929 & \multirow{5}{*}{$2.507 *$} & \multirow{5}{*}{ null } \\
\hline & (2) Teacher & 4.4710 & & \\
\hline & (3) Adm. mentor & 4.7436 & & \\
\hline & (4) Group Leader & 4.7552 & & \\
\hline & (5) Chair & 4.6726 & & \\
\hline \multirow{5}{*}{ IT Integrated Teaching } & (1) Mentor & 4.2016 & \multirow{5}{*}{$4.172 * *$} & \multirow{5}{*}{$(5)>(2)$} \\
\hline & (2) Teacher & 4.0435 & & \\
\hline & (3) Adm. mentor & 4.3231 & & \\
\hline & (4) Group Leader & 4.4438 & & \\
\hline & (5) Chair & 4.4786 & & \\
\hline \multirow{5}{*}{$\begin{array}{l}\text { Communic. \& Repr. of } \\
\text { Information }\end{array}$} & (1) Mentor & 3.9385 & \multirow{5}{*}{$3.417^{*}$} & \multirow{5}{*}{$(5)>(2)$} \\
\hline & (2) Teacher & 3.7609 & & \\
\hline & (3) Adm. mentor & 4.0769 & & \\
\hline & (4) Group Leader & 4.1719 & & \\
\hline & (5) Chair & 4.3571 & & \\
\hline \multirow{5}{*}{ Entirety } & (1) Mentor & 4.2978 & \multirow{5}{*}{$5.001 * *$} & \multirow{5}{*}{$\begin{array}{l}(4)>(2) \\
(5)>(2)\end{array}$} \\
\hline & (2) Teacher & 4.1014 & & \\
\hline & (3) Adm. mentor & 4.4174 & & \\
\hline & (4) Group Leader & 4.4696 & & \\
\hline & (5) Chair & 4.5388 & & \\
\hline
\end{tabular}

Position made significant difference $(F=5.001, p<0.01)$ in entirety of IL. After post comparison by employing Scheffè method, we found that the IL of teachers with position Group Leader and Chair were higher than Teacher as indicated in Table III.

Position made significant difference $(F=6.505, p<0.001)$ in the facet of ability of operating hardware/software. After post comparison by employing Scheffè method, we found that the ability of operating hardware/software with position Mentor, Administrative Mentor, Group Leader, and Chair was better than Teacher.

Position made significant difference $(F=4.172, p<0.01)$ in the facet of IT Integrated Teaching. After post comparison by employing Scheffè method, we found that IT integrated teaching of Chair was better than Teacher.
Position made significant difference $(F=3.417, p<0.05)$ in the facet of communication \& representation of information. After post comparison by employing Scheffè method, we found that communication \& representation of information of Chair was better than Teacher.

School of scale made significant difference $(F=3.642, p<$ $0.05)$ in entirety of IL. After post comparison by employing Scheffè method, we found that the IL of teachers with 25 of school of scale was higher than 6 or less.

School of scale made significant difference $(F=4.325, p<$ 0.01 ) in the facet of ability of network application. After post comparison by employing Scheffè method, we found that the ability of network application with 13-24 school of scale was better than 6 or less.

School of scale made significant difference $(F=3.637, p<$ 
0.05) in the facet of IT integrated teaching. After post comparison by employing Scheffè method, we found that the ability of IT integrated teaching with 25 or more school of scale was better than 6 or less.

Average Computer Use Time per Week per Person made significant difference $(F=13.75, p<0.001)$ in entirety of IL. After post comparison by employing Scheffè method, we found that the IL of teachers with 6-10 hours and 11 hours or more was higher than 0-5 hours as indicated in Table IV.

TABLE IV: AVERAge COMPUTER USE TIME PER WEEK OF TEACHERS' ATTITUDES TOWARDS E-LEARNING

\begin{tabular}{|c|c|c|c|c|}
\hline Facet & Age & AVG & F Value & $\begin{array}{l}\text { Post } \\
\text { Comparis } \\
\text { on }\end{array}$ \\
\hline \multirow{3}{*}{$\begin{array}{l}\text { Ability of } \\
\text { Operating } \\
\text { HW/SW }\end{array}$} & (1) $0-5$ hours & 4.2348 & \multirow{3}{*}{$16.646^{* * *}$} & \multirow{3}{*}{$\begin{array}{l}(3)>(1) \\
(3)>(2)\end{array}$} \\
\hline & (2) 6-10hours & 4.4306 & & \\
\hline & (3) $>=11$ hours & 4.6780 & & \\
\hline \multirow{3}{*}{$\begin{array}{l}\text { Ability of } \\
\text { Network } \\
\text { Application }\end{array}$} & (1) $0-5$ hours & 4.1087 & \multirow{3}{*}{$6.848 * *$} & \multirow{3}{*}{$(3)>(1)$} \\
\hline & (2) 6-10hours & 4.2454 & & \\
\hline & (3) $>11$ hours & 4.4200 & & \\
\hline \multirow{3}{*}{$\begin{array}{l}\text { Recognitio } \\
n \text { of IT }\end{array}$} & (1) $0-5$ hours & 4.5362 & \multirow{3}{*}{$6.299 * *$} & \multirow{3}{*}{$\begin{array}{l}(3)>(1) \\
(3)>(2)\end{array}$} \\
\hline & (2) 6-10hours & 4.5417 & & \\
\hline & (3) $>=11$ hours & 4.7217 & & \\
\hline \multirow{3}{*}{$\begin{array}{l}\text { IT } \\
\text { Integrated } \\
\text { Teaching } \\
\end{array}$} & (1) $0-5$ hours & 4.0261 & \multirow{3}{*}{$11.294 * * *$} & \multirow{3}{*}{$\begin{array}{l}(3)>(1) \\
(3)>(2)\end{array}$} \\
\hline & (2) 6-10hours & 4.2028 & & \\
\hline & (3) 11 hours & 4.4160 & & \\
\hline \multirow{3}{*}{$\begin{array}{l}\text { Communic. } \\
\& \text { Repr. of } \\
\text { Info. }\end{array}$} & (1) $0-5$ hours & 3.7283 & \multirow{3}{*}{$6.612 * *$} & \multirow{3}{*}{$(3)>(1)$} \\
\hline & (2) 6-10hours & 3.9931 & & \\
\hline & (3) 11 hours & 4.1650 & & \\
\hline \multirow{3}{*}{ Entirety } & (1) $0-5$ hours & 4.1268 & \multirow{3}{*}{$13.750 * * *$} & \multirow{3}{*}{$\begin{array}{l}(3)>(1) \\
(3)>(2)\end{array}$} \\
\hline & (2) 6-10hours & 4.2827 & & \\
\hline & (3) $>=11$ hours & 4.4801 & & \\
\hline
\end{tabular}

$* * p<0.01 \quad * * * p<0.001$

\section{Impact of Background Variables and Attitudes} towards e-Learning

In the facet of confidence of e-learning, sex made significant difference $(t=2.807, p<0.01)$. Based on the average, the confidence of e-learning of male was higher than female. In the facet of anxiety of e-learning, sex made significant difference $(t=3.758, p<0.001)$. Based on the average, the confidence of e-learning of female was higher than male. In the facet of attitudes towards e-learning, sex made significant difference $(t=2.778, p<0.01)$. Based on the average, the attitudes towards e-learning of male was higher than female. In the facet of practicality of e-learning, age made significant difference $(F=3.984, p<0.05)$. After post comparison by employing Scheffè method, we found that the practicality of e-learning of age less than 40 was higher than age older than 50 and age didn't make no significant difference in the facet of attitudes towards e-learning of entirety. Seniority made no significant difference in the facet of attitudes towards e-learning of entirety and other facets of attitudes towards e-learning. Educational background made no significant difference in the facet of attitudes towards e-learning of entirety and other facets of attitudes towards e-learning. The holistic attitudes towards e-learning indicated significant difference $(F=$ 7.346, $p<0.001)$ for different position. After post comparison by employing Scheffè method, we found that the attitudes towards e-learning of the position Teacher \& chair was higher than Teacher as indicated in Table V.

TABLE V: ATTITUDES TOWARDS E-LEARNING BY POSITION

\begin{tabular}{|c|c|c|c|c|}
\hline Facet & Age & AVG & $\begin{array}{c}\mathrm{F} \\
\text { Value }\end{array}$ & $\begin{array}{c}\text { Post } \\
\text { Comparison }\end{array}$ \\
\hline \multirow{5}{*}{$\begin{array}{l}\text { Affection } \\
\text { of } \\
\text { e-learning }\end{array}$} & (1) Mentor & 3.7527 & \multirow{5}{*}{$4.594 * *$} & \multirow{5}{*}{$\begin{array}{l}(5)>(1) \\
(5)>(2)\end{array}$} \\
\hline & (2) Teacher & 3.5725 & & \\
\hline & (3) Adm. mentor & 4.0641 & & \\
\hline & (4) Group Leader & 3.9531 & & \\
\hline & (5) Chair & 4.1845 & & \\
\hline \multirow{5}{*}{$\begin{array}{l}\text { Confidence } \\
\text { of } \\
\text { e-learning }\end{array}$} & (1) Mentor & 4.0464 & \multirow{5}{*}{$5.793 * * *$} & \multirow{5}{*}{$\begin{array}{l}(5)>(1) \\
(5)>(2)\end{array}$} \\
\hline & (2) Teacher & 3.8768 & & \\
\hline & (3) Adm. mentor & 4.2949 & & \\
\hline & (4) Group Leader & 4.2656 & & \\
\hline & (5) Chair & 4.4226 & & \\
\hline \multirow{5}{*}{$\begin{array}{l}\text { Anxiety of } \\
\text { e-learning }\end{array}$} & (1) Mentor & 2.8361 & \multirow{5}{*}{$5.039 * *$} & \multirow{5}{*}{$\begin{array}{l}(5)>(1) \\
(5)>(2)\end{array}$} \\
\hline & (2) Teacher & 2.4783 & & \\
\hline & (3) Adm. mentor & 3.1346 & & \\
\hline & (4) Group Leader & 3.1406 & & \\
\hline & (5) Chair & 3.4464 & & \\
\hline \multirow{5}{*}{$\begin{array}{l}\text { Practicality } \\
\text { of } \\
\text { e-learning }\end{array}$} & (1) Mentor & 4.0143 & \multirow{5}{*}{2.211} & \\
\hline & (2) Teacher & 3.7391 & & \\
\hline & (3) Adm. mentor & 4.0385 & & \\
\hline & (4) Group Leader & 4.1328 & & \\
\hline & (5) Chair & 4.2411 & & \\
\hline \multirow{5}{*}{ Entirety } & (1) Mentor & 3.7098 & \multirow{5}{*}{$7.346 * * *$} & \multirow{5}{*}{$\begin{array}{l}(4)>(2) \\
(5)>(1) \\
(5)>(2)\end{array}$} \\
\hline & (2) Teacher & 3.4783 & & \\
\hline & (3) Adm. mentor & 3.9423 & & \\
\hline & (4) Group Leader & 3.9203 & & \\
\hline & (5) Chair & 4.1196 & & \\
\hline
\end{tabular}

TABLE VI: AVERAge COMPUTER USE TIME PER WEEK PER PERSON OF ATTITUDES TOWARDS E-LEARNING

\begin{tabular}{|c|c|c|c|c|}
\hline Facet & Age & AVG & F Value & $\begin{array}{l}\text { Post } \\
\text { Comparis } \\
\text { on }\end{array}$ \\
\hline \multirow{3}{*}{$\begin{array}{l}\text { Affection } \\
\text { of } \\
\text { e-learning }\end{array}$} & (1) $0-5$ hours & 3.5145 & \multirow{3}{*}{$11.720 * * *$} & \multirow{3}{*}{$\begin{array}{l}(3)>(1) \\
(3)>(2)\end{array}$} \\
\hline & (2) 6-10hours & 3.7801 & & \\
\hline & (3) $>11$ hours & 4.0267 & & \\
\hline \multirow{3}{*}{$\begin{array}{c}\text { Confidenc } \\
\text { e of } \\
\text { e-learning }\end{array}$} & (1) $0-5$ hours & 3.8116 & \multirow{3}{*}{$15.786 * * *$} & \multirow{3}{*}{$\begin{array}{l}(2)>(1) \\
(3)>(1) \\
(3)>(2)\end{array}$} \\
\hline & (2) 6-10hours & 4.0903 & & \\
\hline & (3) $>11$ hours & 4.2917 & & \\
\hline \multirow{3}{*}{$\begin{array}{l}\text { Anxiety of } \\
\text { e-learning }\end{array}$} & (1) 0-5 hours & 2.2989 & \multirow{3}{*}{$18.907 * * *$} & \multirow{3}{*}{$\begin{array}{l}(2)>(1) \\
(3)>(1)\end{array}$} \\
\hline & (2) 6-10hours & 2.9722 & & \\
\hline & (3) $>11$ hours & 3.2100 & & \\
\hline \multirow{3}{*}{$\begin{array}{c}\text { Practicality } \\
\text { of } \\
\text { e-learning }\end{array}$} & (1) $0-5$ hours & 3.8424 & \multirow{3}{*}{$4.147^{*}$} & \multirow{3}{*}{$(3)>(1)$} \\
\hline & (2) 6-10hours & 3.9861 & & \\
\hline & (3) $>11$ hours & 4.1550 & & \\
\hline \multirow{3}{*}{ Entirety } & (1) $0-5$ hours & 3.4261 & \multirow{3}{*}{$21.193 * * *$} & \multirow{3}{*}{$\begin{array}{l}(2)>(1) \\
(3)>(1) \\
(3)>(2)\end{array}$} \\
\hline & (2) 6-10hours & 3.7528 & & \\
\hline & (3) $>11$ hours & 3.9685 & & \\
\hline
\end{tabular}

Position made significant difference in the facets of affection of e-learning and confidence of e-learning. After post comparison by employing Scheffè method, we found that the position Teacher \& chair was higher than Mentor and Teacher in the facets of affection of e-learning and confidence of e-learning. It made significant difference in the facets of anxiety of e-learning $(F=4.172, p<0.01$.) After post comparison by employing Scheffè method, we found that the position Mentor and Teacher was higher than Teacher $\&$ chair in the facet of anxiety of e-learning. It made no significant difference $(F=2.211, p>0.05)$ in the facets of practicality of e-learning. 
School of scale made no significant difference $(F=1.390$, $p>0.05)$ in the facets of attitudes towards e-learning of entirety.

Computer average use time per week per person made significant difference $(F=21.193, p<0.001)$ in the facets of attitudes towards e-learning of entirety. After post comparison by employing Scheffè method, we found that 6-10 hours and more than 11 hours of computer average use time per week per person in the facet of attitudes towards e-learning of entirety was higher than 0-5 hours as showed in Table VI.

It made significant difference $(F=11.720, p<0.001)$ in the facets of affection of e-learning. After post comparison by employing Scheffè method, we found that more than 11 hours of computer average use time per week per person was higher than 0-5 hours and 6-10 hours in the facet of affection of e-learning. It made significant difference $(F=15.786, p<$ $0.001)$ in the facets of confidence of e-learning. After post comparison by employing Scheffè method, we found that more than 11 hours of computer average use time per week per person was higher than 0-5 hours and 6-10 hours and 6-10 hours was higher than 0-5 hours in the facet of confidence of e-learning. It made significant difference $(F=$ $18.907, p<0.001)$ in the facet of anxiety of e-learning. After post comparison by employing Scheffè method, we found that 0-5 hours of computer average use time per week per person was higher than 6-10 hours and more than 11 hours in the facet of anxiety of e-learning. It also made significant difference $(F=4.147, p<0.05)$ in the facet of practicality of e-learning. After post comparison by employing Scheffè method, we found that more than 11 hours of computer average use time per week per person was higher than 0-5 hours in the facet of practicality of e-learning.

\section{Correlation Analysis of Teachers' IL and Attitudes towards e-Learning}

In this section, we elucidated correlation analysis of elementary teachers' IL and Attitudes towards E-learning by employing Pearson's Correlation to conduct the analysis.

Based on the results as indicated in Table VII, the level of significance of IL arrived at 0.01 in the facet of entirety and five facets of ability of operating hardware/software, ability of network application, recognition of IT, IT integrated teaching, and communication and representation of information were highly correlated, which indicated that the better the abilities of five facets, the more positive and aggressive the ability of IL.

TABLE VII: ENTIRETY AND INDIVIDUAL CORRELATION ANALYSIS OF IL

\begin{tabular}{|c|c|c|c|c|c|c|}
\hline Facet & $\begin{array}{l}\text { Ability of Oper } \\
\text { HW/SW }\end{array}$ & $\begin{array}{l}\text { Ability of NW } \\
\text { App }\end{array}$ & Recognition of IT & $\begin{array}{l}\text { IT Integrated } \\
\text { Teaching }\end{array}$ & $\begin{array}{l}\text { Communic. and Repr. } \\
\text { of Info. }\end{array}$ & Entirety \\
\hline $\begin{array}{l}\text { Ability of Oper. } \\
\text { HW/SW }\end{array}$ & 1 & & & & & \\
\hline $\begin{array}{l}\text { Ability of NW } \\
\text { App. }\end{array}$ & $0.653^{* *}$ & 1 & & & & \\
\hline $\begin{array}{l}\text { Recognition of } \\
\text { IT }\end{array}$ & $0.635^{* *}$ & $0.568 * *$ & 1 & & & \\
\hline $\begin{array}{l}\text { IT Integrated } \\
\text { Teaching }\end{array}$ & $0.678^{* *} *$ & $0.768 * *$ & $0.544 * *$ & 1 & & \\
\hline $\begin{array}{l}\text { Communic. \& } \\
\text { Repr. of Info. }\end{array}$ & $0.507 * *$ & $0.484 * *$ & $0.372^{* *}$ & $0.577 * *$ & 1 & \\
\hline Entirety & $0.838^{* *}$ & $0.844 * *$ & $0.724 * *$ & $0.875^{* *}$ & $0.744 * *$ & 1 \\
\hline
\end{tabular}

$* *$ Correlation Significance at Level of Significance $=0.01$ (both ends)

TABLE VIII: CORRELATION ANALYSIS OF ATTITUDES TOWARDS E-LEARNING

\begin{tabular}{|c|c|c|c|c|}
\hline Facet & Affection & Confidence & Anxiety & Practicality \\
\hline Affection & 1 & & & \\
\hline Confidence & $0.775^{* *}$ & 1 & 1 & \\
\hline Anxiety & $0.301^{* *}$ & $0.395^{* *}$ & $0.164^{*}$ & \\
\hline Practicality & $0.712^{* *}$ & $0.562^{* *}$ & $0.624^{* *}$ & 1 \\
\hline Entirety & $0.891^{* *}$ & $0.870^{* *}$ & \multirow{2}{*}{$0.743^{* *}$} \\
\hline
\end{tabular}

$* *$ Correlation Significance at Level of Significance $=0.01$ (both ends)

TABLE IX: CORRELATION OF IL AND ATTITUDES TOWARDS E-LEARNING

\begin{tabular}{|c|c|c|c|c|c|}
\hline Facet & Affection & Confidence & Anxiety & Practicality & Entirety \\
\hline Ability of Oper H.W./SW & $0.543^{* *}$ & $0.593^{* *}$ & $0.358^{* *}$ & $0.467^{* *}$ & $0.624^{* *}$ \\
\hline Ability of Network App & $0.594^{* *}$ & $0.624^{* *}$ & $0.289^{* *}$ & $0.505^{* *}$ & $0.638^{* *}$ \\
\hline Recognition of IT & $0.390 * *$ & $0.481^{* *}$ & $219^{* *}$ & $0.374 * *$ & $0.461^{* *}$ \\
\hline IT Integrated Teaching & $0.653^{* *}$ & $645^{* *}$ & $0.239 * *$ & $0.524 * *$ & $0.653^{* *}$ \\
\hline Communic. \& Repr of Info. & $0.527 * *$ & $0.479 * *$ & $0.160^{*}$ & $0.465^{* *}$ & $0.514 * *$ \\
\hline Entirety & $0.673^{* *}$ & $0.692 * *$ & $0.304 * *$ & $0.580^{* *}$ & $0.712 * *$ \\
\hline
\end{tabular}

**Correlation Significance at Level of Significance $=0.01$ (both ends) 


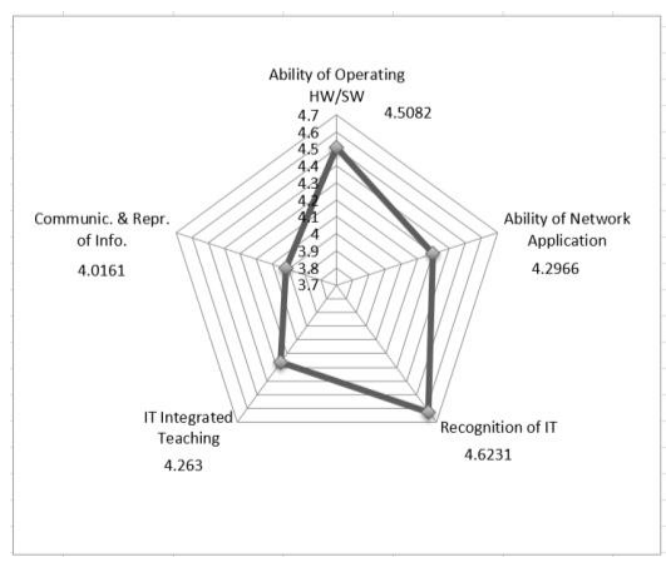

Fig. 3. Radar graph of trend of entirety of IL.

Based on the results as indicated in Table VIII, the level of significance of attitudes towards e-learning in the facet of entirety and four facets of affection, confidence, anxiety, and practicality of e-learning were highly correlated, which indicated that the better the abilities of four facets, the more positive and aggressive the attitudes towards e-learning.

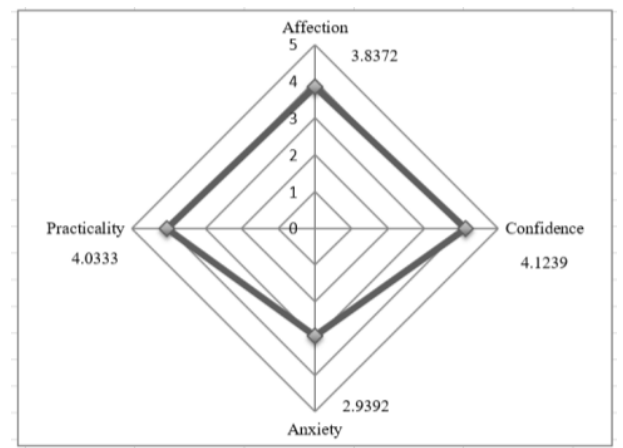

Fig. 4. Radar graph of trend of entirety of attitudes towards e-learning.

Based on the results as indicated in Table IX, the correlation coefficient of entirety of IL and attitudes towards e-learning was $0.712, * * p<0.01$, which indicated highly correlated. In other words, the better the IL, the better the attitudes towards e-learning.

\section{CONCLUSIONS AND SUGGESTIONS}

\section{A. Conclusions}

Teachers' IL and attitudes towards e-learning in Chiayi County, Taiwan ranked in middle-upper level. In the aspect of IL, the facets of recognition of IT ranked the first and ability of operating hardware/software the second as indicated in Fig. 3. In the aspect of IL, the facets of confidence of e-learning ranked the first, practicality of e-learning the second, and anxiety of e-learning the last as indicated in Fig. 4.

Position, school of scale, and average computer use time per week made significant difference for entire IL. Sex, position, and average computer use time per week made significant difference for entirety of attitudes towards e-learning. The correlation coefficient of entirety of IL and attitudes towards e-learning was 0.712 , **p $<0.01$, which indicated highly correlated. Teachers' attitudes towards e-learning was affected by IL in which the facet of IT integrated teaching ranked the first and ability of network application the second.

\section{B. Suggestions}

1) Elementary teachers should continue to enhance IL to integrate IT into teaching activities in a wide variety of disciplines and make the teaching activities more lively, vivid, and vigorous to achieve the teaching effect.

2) In the aspect of teachers' information ability, we suggest hands-on workshop be held to enhance the ability of communication and presentation of information, which was weak indicated in this research, by using peer learning, collaborative team, and teaching media produced by modern technical products to increase the convenience and safety of using IT facilities and interest of learning for students, promote the growth of expertise, and advance the teaching effect for teachers.

3) Elementary teachers should participate in e-learning to increase the ability of life-time learning. Based on our research results, the IL of elementary teachers was relatively passive in the facet of attitudes towards e-earning and weak in the facet of anxiety of e-learning. Sex and position made significant difference. We suggested that administration should establish online learning community, encourage teachers to actively participate and give guidance so that the teachers may communicate, discuss, and consult with students to learn and find the solution to the problems, increase the motives of participating in e-learning, and enhance the affection and decrease the anxiety of e-learning.

4) Teachers of age 50 or more should participate actively in e-learning to solidify own ability of operating information, grasp emerging teaching information and social wave, and promote the ability of life-time learning.

5) Until the end of 2013, due to the changing society, under the impact of geographic environment and low birth rate, the elementary school of 6 or less school of scare in Chiayi County accounted for $66 \%$. One of our researchers from an elementary school in Chiayi County found that the network information facilities and computers of schools with low school of scale were old-fashioned, down frequently, and unsteady of network bandwidth that decreased the intention of participating in e-learning. Therefore, we suggest that the county government should be substantial in computer and network information facilities to be utilized on campus in order to enhance the IL and intention of e-learning of teachers and administrative staff and shorten the digital gap caused by the school of scale.

\section{ACKNOWLEDGMENT}

This work was supported in part by Ministry of Science and Technology, Taiwan, under Grant no. MOST 105-2221-E-274-002 and MOST 104-2221-E-274 -001.

\section{REFERENCES}

[1] Department of Statistics. (2014). [Online]. Available: http://statis.moi.gov.tw/micst/stmain.jsp?sys $=100$

[2] Wen-Chuan Lin and Shu-Ching Yang, "Information literacy and the way of promotion of it for teachers in society of knowledge economy," Journal of General Education, vol. 3, pp. 13-32, 2003. 
[3] C. R. McClure, "Network literacy: A role of libraries?" Information Technology and Libraries, vol. 13, pp. 116-117, 1994.

[4] T.-M. Chuang, "Educational curriculum based on information literacy using library - Implementation pattern by Shih Hsin University library," Shu Yuan Quarterly, vol. 35, pp. 27-36, 1998.

[5] M.-M. Wu, "Everybody needs information literacy in the information era," Social Education Bimonthly Publication, vol. 73, pp. 4-5, 1996.

[6] M.-T. Lin, "A study of relationship between information literacy and teaching self-efficacy of elementary school teachers, Changhua County," Master thesis, Graduate School of Education, National Chung Cheng University, 2007.

[7] M.-M. Wu, "Current state and future development of e-learning," Library Science and Information Science, vol. 30, pp. 92-106, 2004.

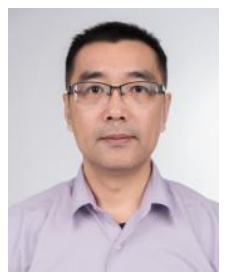

York M. Sun is currently a lecturer in the Departmen of Applied Digital Media at WuFeng University, Min-Hsiung, Chiayi County, Taiwan. He has over 10 years of teaching, research, and practice experience in the area of Information Systems. His current research interests include e-learning, digital media design, and digital photography.

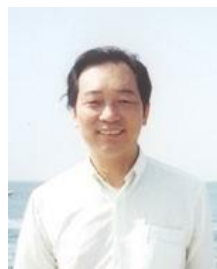

Rong Jou Yang received the bachelor of science in chemistry from National Kaohsiung Normal University, Taiwan in 1978 and Master of Science in computer science from the University of Texas at El Paso in 1985 . He is currently a potential Ph.D. student of The University of Texas at El Paso, El Paso, Texas, USA

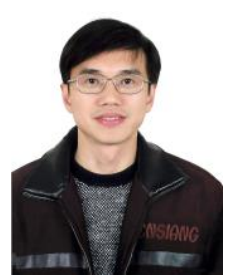

Hann-Jang Ho received his B.S. and M.S. degrees from National Taiwan University of Science and Technology in 1988 and 1990 respectively and the $\mathrm{Ph} . \mathrm{D}$. degree in computer science and information engineering from National Chung Cheng University, Taiwan, ROC in 2003. He is currently a professor in the Department of Applied Digital Media at WuFeng University, Min-Hsiung, Chiayi County, Taiwan, ROC.

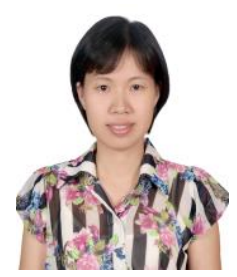

Yu-Fen Chang received her bachelor of industrious education and technology from National Changhua University of Education in 1998 and the master of applied digital media from WuFeng University in 2015. She is currently a teacher of Guogou Elementary School, Budai, Chiayi County, Taiwan. 